\title{
Deformation based design of steel and composite structural elements
}

\author{
L. Gardner ${ }^{a *}$ and X. Yun ${ }^{a}$ \\ aDepartment of Civil and Environmental Engineering, Imperial College London, UK \\ *corresponding author, e-mail address: Leroy.gardner@imperial.ac.uk
}

\begin{abstract}
Steel and composite structures are traditionally designed through strength based calculations. An alternative approach is to consider deformation capacity. Deformation based design enables a more accurate allowance to be made for the spread of plasticity and allows strain hardening to be considered in a systematic manner. Importantly, the level of deformation required by the structure at ultimate limit state to reach the required design capacity can also be assessed. In composite construction, deformation based design enables a more rigorous assessment to be made of the development of strength in the structural system taking due account of the compatibility between the constituent materials. In this paper, recent developments to the deformation based continuous strength method for steel and composite design are described. Comparisons of capacities obtained from experiments and numerical simulations with those predicted using the continuous strength method are presented and discussed. Recommendations for future work on this topic are also set out.
\end{abstract}

Keywords: Compatibility; deformation based; steel; steel-concrete composite; strain based.

\section{Introduction}

Structural design codes for steel and steelconcrete composite structures are typically strength-based. The criteria for assessing the acceptability of the structural design at ultimate limit state involve comparisons between the factored member forces and the factored resistances. Checks, typically under unfactored loads, are also carried out to assess the acceptability of the performance of the structure in service. However, an explicit assessment of the deformation of the structure and, for composite construction, the compatibility of deformations between the constituent elements, at ultimate limit state, is not typically performed. This can lead to (1) highly inconsistent deformation demands being placed on different structural elements prior to the attainment of their design resistance, (2) non-ductile failure modes and (3) hindrance to the systematic exploitation of the beneficial influence of the spread of plasticity and strain hardening.

In this paper, recent developments to the deformation based continuous strength method
(CSM) for steel and steel-concrete composite design are described, and advantages over existing design methods are highlighted.

\section{Continuous strength method}

The key features of the CSM are (1) a base curve that defines the maximum level of strain $\varepsilon_{\mathrm{csm}}$ that a cross-section can endure prior to failure by (inelastic) local buckling as a function of the cross-section slenderness and (2) the adoption of a material model that allows for the beneficial influence of strain hardening.

\subsection{CSM design base curve}

The CSM design base curve provides a continuous relationship between the strain ratio $\varepsilon_{\mathrm{csm}} / \varepsilon_{\mathrm{y}}$ (i.e., deformation capacity) and the crosssection slenderness $\bar{\lambda}_{\mathrm{p}}$, where $\varepsilon_{\mathrm{y}}$ is the material yield strain equal to $f_{\mathrm{y}} / E$, with $f_{\mathrm{y}}$ being the steel yield stress and $E$ being the Young's modulus. The cross-section slenderness $\bar{\lambda}_{\mathrm{p}}$ is defined in a non-dimensional form by Eq. (1), where $\sigma_{\mathrm{cr}}$ is the elastic buckling stress which should preferably be determined for the full cross-section either 
using numerical methods, such as the finite strip software CUFSM [1], or approximate analytical methods [2].

$\bar{\lambda}_{\mathrm{p}}=\sqrt{f_{\mathrm{y}} / \sigma_{\mathrm{cr}}}$

Experimental data from stub column tests and four-point bending tests on hot-rolled carbon steel, cold-formed carbon steel, high strength steel and stainless steel sections have been collated and plotted in Fig. 1 on a graph of strain ratio $\varepsilon_{\mathrm{csm}} / \varepsilon_{\mathrm{y}}$ versus $\bar{\lambda}_{\mathrm{p}}$. The test data for the different materials show a clear trend of reducing deformation capacity (i.e. lower $\varepsilon_{\mathrm{csm}} / \varepsilon_{\mathrm{y}}$ ) with increasing cross-section slenderness $\bar{\lambda}_{\mathrm{p}}$. The CSM base curve is given by Eq. (2), where $\varepsilon_{\mathrm{u}}$ is the strain corresponding to the ultimate tensile strength $f_{\mathrm{u}}$, and can be seen to provide good predictions of normalised deformation capacity for all the considered materials. Two upper bounds have been placed on the predicted CSM strain ratio $\varepsilon_{\mathrm{csm}} / \varepsilon_{\mathrm{y}}$; the first limit of 15 is related to the material ductility requirement according to EN 1993-1-1 (EC3) [3] and prevents excessive deformations, and the second limit of $C_{1} \varepsilon_{\mathrm{u}}$, where $C_{1}$ is a coefficient corresponding to the adopted CSM material model as described in the subsequent section, defines a 'cut-off' strain to avoid over-predictions of material strength. It is noted that the CSM base curve (Eq. (2)) applies to non-slender cross-sections where $\bar{\lambda}_{\mathrm{p}} \leq 0.68$, with $\bar{\lambda}_{\mathrm{p}}=0.68$ being the transaction point between non-slender and slender sections [4], though extension the base curve to slender crosssections has also recently been presented [5].

$$
\frac{\varepsilon_{\mathrm{csm}}}{\varepsilon_{\mathrm{y}}}=\frac{0.25}{\bar{\lambda}_{\mathrm{p}}^{3.6}} \text {, but } \frac{\varepsilon_{\mathrm{csm}}}{\varepsilon_{\mathrm{y}}} \leq \min \left(15, \frac{C_{1} \varepsilon_{\mathrm{u}}}{\varepsilon_{\mathrm{y}}}\right)
$$

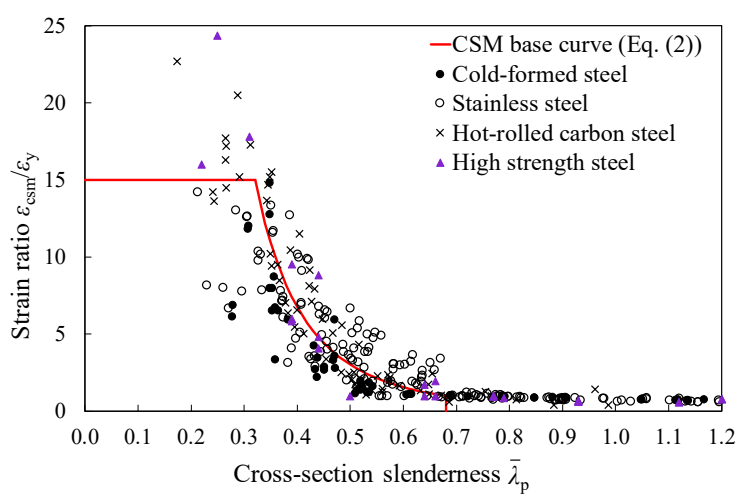

Fig. 1. CSM base curve for non-slender crosssections.

\subsection{CSM material models}

An elastic, linear hardening material model has been employed throughout the development of the CSM to represent the strain hardening response of metallic materials with rounded stress-strain behaviour, such as stainless steel, aluminium and cold-formed steel. However, this bi-linear material model is unsuitable for hotrolled carbon steels due to the presence of the characteristic yield plateau, with strain hardening not commencing until the attainment of strain hardening strain $\varepsilon_{\text {sh. }}$. Thus, the quadlinear material model proposed in [6], as illustrated in Fig. 2 and described in Eq. (3), is adopted as the CSM material model for hotrolled carbon steels, taking account of both the yield plateau and the strain hardening.

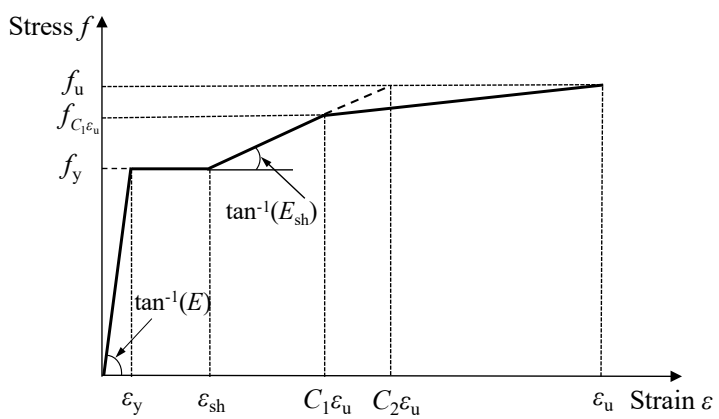

Fig. 2. The quad-linear material model for hotrolled carbon steels.

$$
f(\varepsilon)= \begin{cases}E \varepsilon & \text { for } \varepsilon \leq \varepsilon_{\mathrm{y}} \\ f_{\mathrm{y}} & \text { for } \varepsilon_{\mathrm{y}}<\varepsilon \leq \varepsilon_{\mathrm{sh}} \\ f_{\mathrm{y}}+E_{\mathrm{sh}}\left(\varepsilon-\varepsilon_{\mathrm{sh}}\right) & \text { for } \varepsilon_{\mathrm{sh}}<\varepsilon \leq C_{1} \varepsilon_{\mathrm{u}} \\ f_{C_{\mathrm{l}} \varepsilon_{\mathrm{u}}}+\frac{f_{\mathrm{u}}-f_{C_{1} \varepsilon_{\mathrm{u}}}}{\varepsilon_{\mathrm{u}}-C_{1} \varepsilon_{\mathrm{u}}}\left(\varepsilon-C_{1} \varepsilon_{\mathrm{u}}\right) & \text { for } C_{\mathrm{l}} \varepsilon_{\mathrm{u}}<\varepsilon \leq \varepsilon_{\mathrm{u}}\end{cases}
$$

Four material coefficients, $C_{1}, C_{2}, C_{3}$ and $C_{4}$, are used in the material model; $C_{1}$ defines a 'cutoff' strain to avoid over-predictions of material strength and is also included in the CSM base curve (Eq. (2)); $C_{2}$ is used in Eq. (4) to define the strain hardening slope $E_{\mathrm{sh}}$; and $C_{3}$ and $C_{4}$ are used in the predictive expression for ultimate strain $\varepsilon_{\mathrm{u}}$ (Eq. (5)), which is also needed for the determination of $E_{\text {sh. }}$. The strain hardening strain $\varepsilon_{\text {sh }}$ for hot-rolled carbon steels may be determined from Eq. (6). Note that the quadlinear material adopts the same definitions for the material coefficients as used in the previous CSM elastic, linear hardening material model, and can indeed be seen as a superset of the previous model, with the principal difference being that the strain hardening strain $\varepsilon_{\text {sh }}$ is equal to the yield strain $\varepsilon_{\mathrm{y}}$ in the CSM elastic, linear 
hardening model, resulting in Eq. (7) for the calculation of $E_{\text {sh. }}$.

$E_{\mathrm{sh}}=\frac{f_{\mathrm{u}}-f_{\mathrm{y}}}{C_{2} \varepsilon_{\mathrm{u}}-\varepsilon_{\mathrm{sh}}}$ for hot-rolled carbon steels

$\varepsilon_{\mathrm{u}}=C_{3}\left(1-\frac{f_{\mathrm{y}}}{f_{\mathrm{u}}}\right)+C_{4}$

but $\varepsilon_{\mathrm{u}} \geq 0.06$ for hot-rolled carbon steels

$\varepsilon_{\mathrm{sh}}=0.1 \frac{f_{\mathrm{y}}}{f_{\mathrm{u}}}-0.055$, but $0.015 \leq \varepsilon_{\mathrm{u}} \leq 0.03$

$E_{\mathrm{sh}}=\frac{f_{\mathrm{u}}-f_{\mathrm{y}}}{C_{2} \varepsilon_{\mathrm{u}}-\varepsilon_{\mathrm{y}}}$ for stainless steels, aluminium

and cold-formed steels

Recommended values or predictive expressions for the coefficients for the different materials are summarised in Table 1. Detailed information on the derivation of these coefficients is given in [4,6-11].

Table 1. Summary of coefficients for the CSM material model.

\begin{tabular}{lllll}
\hline Material & $C_{1}$ & $C_{2}$ & $C_{3}$ & $C_{4}$ \\
\hline Hot-rolled steel & Eq. (8) & Eq. (9) & 0.60 & 0 \\
Cold-formed steel & 0.40 & 0.45 & 0.60 & 0 \\
Austenitic and duplex & 0.10 & 0.16 & 1.00 & 0 \\
stainless steel & & & \\
Ferritic stainless steel & 0.40 & 0.45 & 0.60 & 0 \\
Aluminium & 0.50 & 0.50 & 0.13 & 0.06 \\
\hline
\end{tabular}

$C_{1}=\frac{\varepsilon_{\mathrm{sh}}+0.25\left(\varepsilon_{\mathrm{u}}-\varepsilon_{\mathrm{sh}}\right)}{\varepsilon_{\mathrm{u}}}$

$$
C_{2}=\frac{\varepsilon_{\mathrm{sh}}+0.4\left(\varepsilon_{\mathrm{u}}-\varepsilon_{\mathrm{sh}}\right)}{\varepsilon_{\mathrm{u}}}
$$

Having introduced the CSM base curve and material models, the development of strength equations for carbon steel and steel-concrete composite design was explored. The most recent research studies into this field are summarised in the following sections.

\section{Recent CSM developments for carbon steel design}

The research detailed below focuses on recent developments to the CSM for application to carbon steel structural elements, including both cold-formed and hot-rolled steels.

\subsection{Cold-formed steels}

Within the CSM design framework, the cross-section resistances in compression or bending are determined utilizing the limiting strain $\varepsilon_{\mathrm{csm}}$ from the CSM design base curve (Eq. (2)), in conjunction with the CSM material model summarised in Section 2.2.

For non-slender cross-sections $\left(\bar{\lambda}_{\mathrm{p}} \leq 0.68\right)$, the CSM cross-section compression resistance $N_{\text {csm }}$ is determined as the product of the gross cross-section area $A$ and the CSM limiting stress $f_{\text {csm }}$, as given by Eq. (10), in which $f_{\text {csm }}$ is calculated from Eq. (11) based on the proposed CSM material model for cold-formed steels [8].

$$
\begin{aligned}
& N_{\mathrm{csm}}=A f_{\mathrm{csm}} \\
& f_{\mathrm{csm}}=f_{\mathrm{y}}+E_{\mathrm{sh}}\left(f_{\mathrm{csm}}-f_{\mathrm{y}}\right)
\end{aligned}
$$

For cross-sections with $\bar{\lambda}_{\mathrm{p}} \leq 0.68$, the crosssection bending resistance $M_{\mathrm{csm}}$ is determined from Eqs. (12) and (13) for major and minor axis bending, respectively, where $W_{\mathrm{pl}}$ is the plastic section modulus, $W_{\mathrm{el}}$ is the elastic section modulus, $\mathrm{y}$ and $\mathrm{z}$ refer to the major and minor axis, respectively, and $\alpha$ is a dimensionless coefficient that depends on the cross-section shape and axis of bending as defined in Table 2 .

$$
\begin{aligned}
M_{\mathrm{csm}, \mathrm{y}}=W_{\mathrm{pl}, y} f_{\mathrm{y}} & {\left[1+\frac{E_{\mathrm{sh}}}{E} \frac{W_{\mathrm{el}, y}}{W_{\mathrm{pl}, y}}\left(\frac{\varepsilon_{\mathrm{csm}}}{\varepsilon_{\mathrm{y}}}-1\right)\right.} \\
& \left.-\left(1-\frac{W_{\mathrm{el}, \mathrm{y}}}{W_{\mathrm{pl}, \mathrm{y}}}\right) /\left(\frac{\varepsilon_{\mathrm{csm}}}{\varepsilon_{\mathrm{y}}}\right)^{\alpha}\right] \\
M_{\mathrm{css}, \mathrm{z}}=W_{\mathrm{pl}, \mathrm{z}} f_{\mathrm{y}} & {\left[1+\frac{E_{\mathrm{sh}}}{E} \frac{W_{\mathrm{el}, \mathrm{z}}}{W_{\mathrm{pl}, \mathrm{z}}}\left(\frac{\varepsilon_{\mathrm{csm}}}{\varepsilon_{\mathrm{y}}}-1\right)\right.} \\
& \left.-\left(1-\frac{W_{\mathrm{el}, \mathrm{z}}}{W_{\mathrm{pl}, \mathrm{z}}}\right) /\left(\frac{\varepsilon_{\mathrm{csm}}}{\varepsilon_{\mathrm{y}}}\right)^{\alpha}\right]
\end{aligned}
$$

Table 2. CSM coefficient factors $\alpha$ and $\beta$ for bending.

\begin{tabular}{cccccc}
\hline & \multicolumn{2}{c}{$\alpha$} & & \multicolumn{2}{c}{$\beta$} \\
\cline { 2 - 3 } \cline { 5 - 6 } & Major & Minor & & Major & Minor \\
\hline I-sections & 2.0 & 1.2 & & 0.08 & 0.05 \\
Box-sections & 2.0 & 2.0 & & 0.08 & 0.08 \\
\hline
\end{tabular}

Work performed in [8] examines the accuracy of the CSM for the design of coldformed steel cross-sections in compression and bending through comparisons against over 600 
test and FE data. The comparisons revealed that the CSM provides more accurate and consistent resistance predictions of cold-formed steel crosssections in compression and bending than the design provisions of EC3. The CSM predicts enhanced resistances over EC3 due to its rational exploitation of the spread of plasticity and strain hardening for non-slender cross-sections, with average enhancements in compressive and bending resistances being $5 \%$ and $3 \%$, respectively, for typical dimensions.

A new design approach for cold-formed steel box sections under combined loading, which adopts similar interaction expressions to those given in EC3 but utilizes the CSM compression and bending resistances as the end points, was also proposed and examined in [8]. The proposed interaction expressions for coldformed steel box sections under major and minor axis bending plus compression are given by Eqs. (14) and (15), respectively, while Eq. (16) was put forward for biaxial bending plus compression, where $M_{\mathrm{Ed}}$ is the applied design bending moment, $M_{\mathrm{R}, \mathrm{csm}}$ is the reduced CSM bending resistance due to the existence of axial load $N_{\mathrm{Ed}}, n_{\mathrm{csm}}$ is the ratio of the design axial load to CSM compression resistance $N_{\mathrm{Ed}} / N_{\mathrm{csm}}, a_{\mathrm{w}}$ and $a_{\mathrm{f}}$ are the ratios of the cross-section web area $A_{\mathrm{w}}$ and flange area $A_{\mathrm{f}}$ to the gross area $A$, respectively, $\varphi$ is the reduction factor for the plateau length, as illustrated in Fig. 3 and given by Eq. (17), and $\alpha_{\mathrm{csm}}$ and $\beta_{\mathrm{csm}}$ are the interaction coefficients for biaxial bending, whose values, which depend on the axial load ratio $n_{\mathrm{csm}}$ and cross-section slenderness $\bar{\lambda}_{\mathrm{p}}$, are given in Table 3.

$$
\begin{aligned}
& M_{\mathrm{R}, \mathrm{csm}, \mathrm{y}}=M_{\mathrm{csm}, \mathrm{y}} \frac{1-n_{\mathrm{csm}}}{1-0.5 \varphi a_{\mathrm{w}}} \leq M_{\mathrm{csm}, \mathrm{y}} \\
& M_{\mathrm{R}, \mathrm{csm}, \mathrm{z}}=M_{\mathrm{csm}, \mathrm{z}} \frac{1-n_{\mathrm{csm}}}{1-0.5 \varphi a_{\mathrm{f}}} \leq M_{\mathrm{csm}, \mathrm{z}} \\
& \left(\frac{M_{\mathrm{Ed}, \mathrm{y}}}{M_{\mathrm{R}, \mathrm{csm}, \mathrm{y}}}\right)^{\alpha_{\mathrm{csm}}}+\left(\frac{M_{\mathrm{Ed}, \mathrm{z}}}{M_{\mathrm{R}, \mathrm{csm}, \mathrm{z}}}\right)^{\beta_{\mathrm{csm}}} \leq 1 \\
& \varphi=1.36-2 \bar{\lambda}_{\mathrm{p}} \leq 1
\end{aligned}
$$

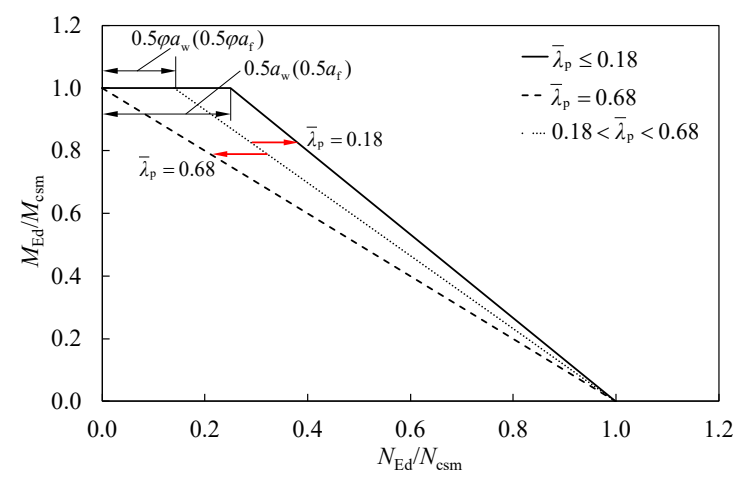

Fig. 3. Proposed design interaction curves for cold-formed steel box sections under uniaxial bending plus compression.

Table 3. Proposed interaction coefficients for coldformed steel box sections subjected to biaxial bending plus compression.

\begin{tabular}{cccc}
\hline & \multicolumn{2}{c}{$\bar{\lambda}_{\mathrm{p}} \leq 0.5$} & $0.5<\bar{\lambda}_{\mathrm{p}} \leq 0.68$ \\
\cline { 2 - 4 } & $n_{\mathrm{csm}}<0.8$ & $0.8<n_{\mathrm{csm}} \leq 1$ & \\
\hline$\alpha_{\mathrm{csm}}$ & $1.45 /\left(1-1.2 n_{\mathrm{csm}}{ }^{2}\right)$ & 6 & $-2.5 \bar{\lambda}_{\mathrm{p}}+2.7$ \\
$\beta_{\mathrm{csm}}$ & $1.45 /\left(1-1.2 n_{\mathrm{csm}^{2}}\right)$ & 6 & $-2.5 \bar{\lambda}_{\mathrm{p}}+2.7$ \\
\hline
\end{tabular}

A total of 12 test results and 1285 complementary finite element (FE) results on cold-formed steel box sections under combined loading has been compared with design predictions using the proposed CSM [8] and EN 1993-1-1. The ratios of the test (or FE) to the predicted capacities $R_{\mathrm{u} \text {,test } / F \mathrm{~F}} / R_{\mathrm{u}, \mathrm{pred}}$, which are graphically defined in Fig. 4, are plotted against the cross-section slenderness $\bar{\lambda}_{\mathrm{p}}$ in Figs 5 and 6 for cold-formed steel box-sections under compression plus biaxial bending. Note that a value of $R_{\mathrm{u}, \text { test } / \mathrm{FE}} / R_{\mathrm{u} \text {,pred }}$ greater than unity means that the test or FE data point lies beyond the interaction curve, thus indicating a safe-sided result. The mean and coefficient of variation (COV) values of $R_{\mathrm{u}, \text { test } / \mathrm{FE}} / R_{\mathrm{u} \text {,pred }}$ from the comparisons are provided in Tables 4 and 5 for cross-sections under compression plus uniaxial bending and biaxial bending, respectively. The statistical values in Tables 4 and 5 clearly indicate that the proposed CSM for cold-formed steel box sections under combined loading provides closer and more consistent predictions of capacity than EC3 through a rational allowance of strain hardening and the adoption of more accurate interaction expressions, i.e. a gradual transition between the bi-linear interaction curve to the linear curve for $\bar{\lambda}_{\mathrm{p}}>$ 0.68 for cross-sections under compression and 
uniaxial bending (see Fig. 3) and a modified nonlinear interaction equation for cross-sections under compression and biaxial bending (see Table 3). The robustness of the CSM predictions for cold-formed steel box-sections under combined loading is also highlighted in Figs 5 and 6.

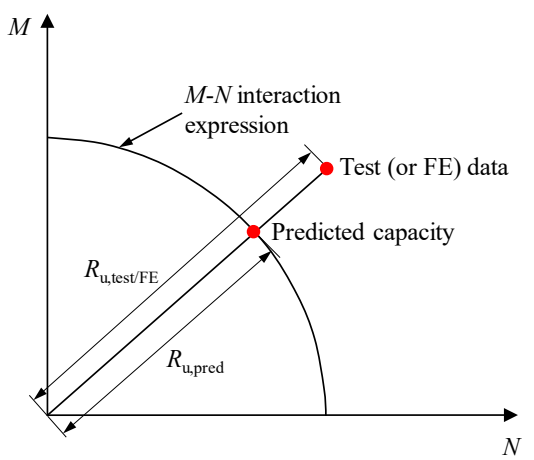

Fig. 4. Graphical definition of $R_{\mathrm{u}, \text { test/FE }}$ and $R_{\mathrm{u}, \mathrm{pred}}$ for the assessment of design provisions.

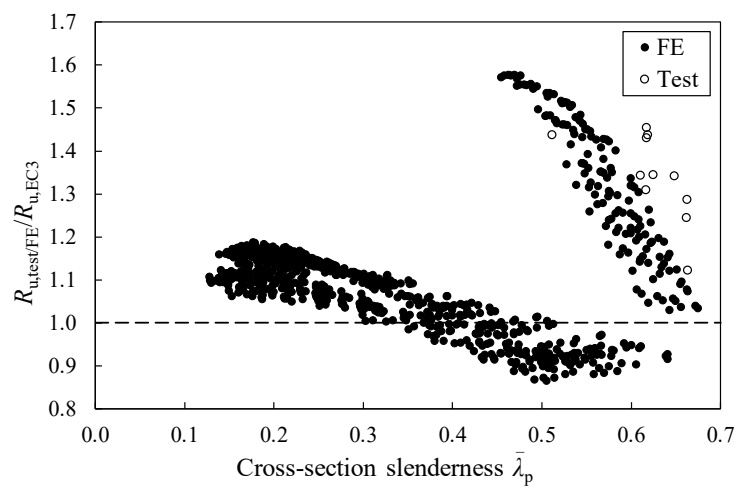

Fig. 5. Comparison of test and FE results with EC3 resistance predictions for crosssections under biaxial bending plus compression.

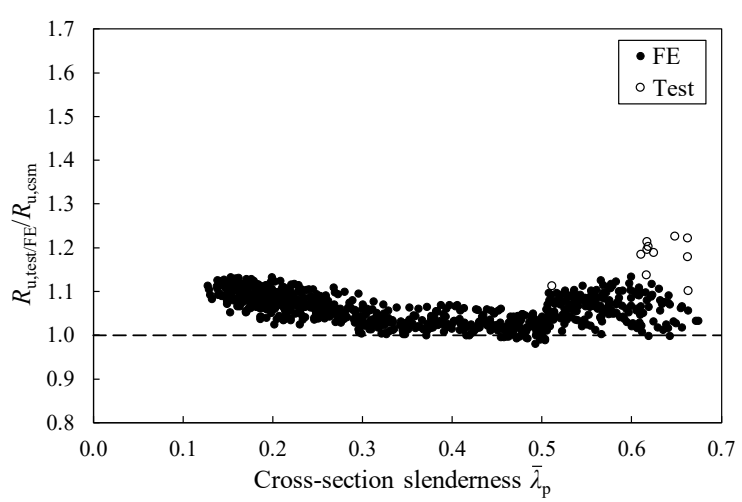

Fig. 6. Comparison of test and FE results with CSM resistance predictions for crosssections under biaxial bending plus compression.
Table 4. Comparison of uniaxial bending plus compression test and FE results with EC3 and CSM predicted strengths.

No. of tests: $1 \quad R_{\mathrm{u}, \text { test } / \mathrm{FE}} / R_{\mathrm{u}, \mathrm{EC} 3} \quad R_{\mathrm{u}, \text { test } / \mathrm{FE}} / R_{\mathrm{u}, \mathrm{csm}}$ No. of FE data: 489

\begin{tabular}{lll} 
Mean & 1.071 & 1.048 \\
COV & 0.078 & 0.039 \\
\hline
\end{tabular}

Table 5. Comparison of biaxial bending plus compression test and FE results with EC3 and CSM predicted strengths.

\begin{tabular}{ccc}
\hline $\begin{array}{c}\text { No. of tests: } 11 \\
\text { No. of FE data: } 796\end{array}$ & $R_{\mathrm{u}, \text { test } / \mathrm{FE}} / R_{\mathrm{u}, \mathrm{EC} 3}$ & $R_{\mathrm{u}, \text { test/FE }} / R_{\mathrm{u}, \mathrm{csm}}$ \\
\hline Mean & 1.111 & \\
COV & 0.131 & 0.034 \\
\hline
\end{tabular}

\subsection{Hot-rolled steels}

The first three stages of the quad-linear material model (see Fig. 2) has been adopted for the development of the CSM for hot-rolled carbon steel cross-sections [9]. The CSM resistance expressions for hot-rolled steel crosssections under compression $N_{\mathrm{csm}}$ and bending $M_{\text {csm }}$ are summarized in this section. A detailed description of the derivation of these equations can be found in [9].

The CSM compression resistance $N_{\text {csm }}$ for a hot-rolled steel non-slender cross-section can be determined using Eq. (10) but $f_{\text {csm }}$ should be calculated from Eq. (18) based on the proposed CSM material model for hot-rolled steels.

$f_{\mathrm{csm}}= \begin{cases}f_{\mathrm{y}} & \text { for } \varepsilon_{\mathrm{y}}<\varepsilon_{\mathrm{csm}} \leq \varepsilon_{\mathrm{sh}} \\ f_{\mathrm{y}}+E_{\mathrm{sh}}\left(\varepsilon_{\mathrm{csm}}-\varepsilon_{\mathrm{sh}}\right) & \text { for } \varepsilon_{\mathrm{sh}}<\varepsilon_{\mathrm{csm}} \leq C_{1} \varepsilon_{\mathrm{u}}\end{cases}$

For cross-sections with $\bar{\lambda}_{\mathrm{p}} \leq 0.68$, the CSM bending resistance $M_{\mathrm{csm}}$ depends upon whether or not strain hardening is experienced (i.e. whether or not $\varepsilon_{\mathrm{csm}}>\varepsilon_{\mathrm{sh}}$ ). If $\varepsilon_{\mathrm{csm}} \leq \varepsilon_{\mathrm{sh}}$, then the cross-section bending resistance $M_{\mathrm{csm}}$ is given by Eqs. (19) and (20) for major and minor axis bending, respectively. EC3 limits the bending resistances of Class 3 cross-sections to the elastic bending moment, which is overly conservative for some Class 3 cross-sections due to the neglect of the spread of plasticity. However, this effect has been considered in Eqs. (19) and (20), which allow for the increasing resistance with increasing deformation capacity (i.e. strain ratio $\left.\varepsilon_{\mathrm{csm}} / \varepsilon_{\mathrm{y}}\right)$. 


$$
\begin{gathered}
M_{\mathrm{csm}, \mathrm{y}}=W_{\mathrm{pl}, \mathrm{y}} f_{\mathrm{y}}\left[1-\left(1-\frac{W_{\mathrm{el}, \mathrm{y}}}{W_{\mathrm{pl}, \mathrm{y}}}\right) /\left(\frac{\varepsilon_{\mathrm{csm}}}{\varepsilon_{\mathrm{y}}}\right)^{\alpha}\right] \\
\text { for } \varepsilon_{\mathrm{csm}} \leq \varepsilon_{\mathrm{sh}} \\
M_{\mathrm{csm}, \mathrm{z}}=W_{\mathrm{pl}, \mathrm{z}} f_{\mathrm{y}}\left[1-\left(1-\frac{W_{\mathrm{el}, \mathrm{z}}}{W_{\mathrm{pl}, \mathrm{z}}}\right) /\left(\frac{\varepsilon_{\mathrm{csm}}}{\varepsilon_{\mathrm{y}}}\right)^{\alpha}\right] \\
\text { for } \varepsilon_{\mathrm{csm}} \leq \varepsilon_{\mathrm{sh}}
\end{gathered}
$$

For the more stocky cross-sections, where $\varepsilon_{\mathrm{csm}}>\varepsilon_{\mathrm{sh}}$, some benefit from strain hardening can also be exploited, and the CSM cross-section bending resistance is given by Eqs. (21) and (22), for major and minor axis bending respectively, where $\alpha$ and $\beta$ are dimensionless coefficients, values of which are given in Table 2.

$$
\begin{gathered}
M_{\mathrm{csm}, \mathrm{y}}=W_{\mathrm{pl}, \mathrm{y}} f_{\mathrm{y}}\left[1-\left(1-\frac{W_{\mathrm{el}, \mathrm{y}}}{W_{\mathrm{pl}, \mathrm{y}}}\right) /\left(\frac{\varepsilon_{\mathrm{csm}}}{\varepsilon_{\mathrm{y}}}\right)^{\alpha}\right. \\
\left.+\beta\left(\frac{\varepsilon_{\mathrm{csm}}-\varepsilon_{\mathrm{sh}}}{\varepsilon_{\mathrm{y}}}\right)^{2} \frac{E_{\mathrm{sh}}}{E}\right] \\
M_{\mathrm{csm}, \mathrm{z}}=W_{\mathrm{pl}, \mathrm{z}} f_{\mathrm{y}}\left[\begin{array}{c}
1-\left(1-\frac{W_{\mathrm{el}, \mathrm{z}}}{W_{\mathrm{pl}, \mathrm{z}}}\right) /\left(\frac{\varepsilon_{\mathrm{csm}}}{\varepsilon_{\mathrm{y}}}\right)^{\alpha} \\
+\beta \varepsilon_{\mathrm{sh}}
\end{array}\right. \\
\left.+\left(\frac{\varepsilon_{\mathrm{csm}}-\varepsilon_{\mathrm{sh}}}{\varepsilon_{\mathrm{y}}}\right)^{2} \frac{E_{\mathrm{sh}}}{E}\right]
\end{gathered}
$$$$
\text { for } \varepsilon_{\mathrm{csm}}>\varepsilon_{\mathrm{sh}}
$$

The accuracy of these resistance functions has been assessed in [9] by comparing the predicted resistances with experimental and FE results for hot-rolled steel cross-sections, including both I-sections and box sections. The comparisons revealed that the CSM generally provides more accurate and consistent predictions than EC3, especially for very stocky cross-sections and for Class 3 sections in bending.

Recent work $[12,13]$ has extended the CSM to cover hot-rolled steel I-sections under combined loading. The proposed CSM for hotrolled steel I-sections under combined loading utilises the same concept as applied to coldformed box sections i.e. adopting similar interaction expressions and coefficients employed in EC3 but replacing the EC3 design resistances for compression and bending with the corresponding CSM resistances. The proposed CSM design equations are summarised as follows:

For hot-rolled steel I-sections under combined compression and uniaxial bending,

$$
\begin{aligned}
M_{\mathrm{R}, \mathrm{csm}, \mathrm{y}}= & M_{\mathrm{csm}, \mathrm{y}} \frac{1-n_{\mathrm{csm}}}{1-0.5 a_{\mathrm{w}}}, \text { but } \leq M_{\mathrm{csm}, \mathrm{y}} \\
M_{\mathrm{R}, \mathrm{csm}, \mathrm{z}}= & \begin{cases}M_{\mathrm{csm}, \mathrm{z}} & \text { for } n_{\mathrm{csm}} \leq a_{\mathrm{w}} \\
M_{\mathrm{csm}, \mathrm{z}}\left[1-\left(\frac{n_{\mathrm{csm}}-a_{\mathrm{w}}}{1-a_{\mathrm{w}}}\right)^{2}\right] & \text { for } n_{\mathrm{csm}}>a_{\mathrm{w}}\end{cases}
\end{aligned}
$$

$a_{\mathrm{w}}=\frac{A_{\mathrm{w}}}{A}$, but $a_{\mathrm{w}} \leq 0.25$

For hot-rolled steel I-sections under combined compression and biaxial bending,

$$
\left(\frac{M_{\mathrm{Ed}, \mathrm{y}}}{M_{\mathrm{R}, \mathrm{csm}, \mathrm{y}}}\right)^{\alpha_{\mathrm{csm}}}+\left(\frac{M_{\mathrm{Ed}, \mathrm{z}}}{M_{\mathrm{R}, \mathrm{csm}, \mathrm{z}}}\right)^{\beta_{\mathrm{css}}} \leq 1 \text { for } \bar{\lambda}_{\mathrm{p}} \leq 0.6
$$

where $\alpha_{\mathrm{csm}}=2$ and $\beta_{\mathrm{csm}}=5 n_{\mathrm{csm}} \geq 1$,

$$
\frac{N_{\mathrm{Ed}}}{N_{\mathrm{csm}}}+\frac{M_{\mathrm{Ed}, \mathrm{y}}}{M_{\mathrm{csm}, \mathrm{y}}}+\frac{M_{\mathrm{Ed}, \mathrm{z}}}{M_{\mathrm{csm}, \mathrm{z}}} \leq 1 \quad \text { for } \bar{\lambda}_{\mathrm{p}}>0.6
$$

The proposed CSM for hot-rolled steel Isections under combined loading has also been found to provide more accurate and consistent resistance predictions than EC3, and extension of the method to cover hot-rolled steel box section under combined loading and indeterminate structures is currently underway.

\section{Recent CSM developments for steel- concrete composite design}

Research $[14,15]$ have begun to investigate the applicability of the CSM to the design of steel-concrete composite elements. Maintaining the basic design philosophy of the CSM, Gardner et al. [14] developed an analytical model to calculate the bending capacity of composite beams (see Fig. 7) with full shear connection under sagging bending moment, allowing for the influence of strain hardening through the CSM material model for hot-rolled steels as described in Section 2.2. The analytical model was derived for one scenario, that being where the neutral axis lies within the concrete slab, as shown in Fig. 7, and the strain at the bottom outer fibre of the steel section reaches the strain hardening strain $\varepsilon_{\text {sh }}$. The resulting CSM design procedure for determining the bending 
resistance of composite beams under sagging moment is summarized in the following four steps:

(1) Determine the neutral axis position $y_{\mathrm{csm}, \mathrm{c}}$, as shown in Fig. 7, assuming that concrete crushing governs the failure (i.e. the maximum outer fibre strain in the concrete slab reaches the limit of $0.0035)$ by solving the quadratic Eq. (28).

$$
\mathrm{B} y_{\mathrm{csm}, \mathrm{c}}^{2}+\mathrm{C} y_{\mathrm{csm}, \mathrm{c}}+\mathrm{D}=0
$$

in which the coefficients $\mathrm{B}, \mathrm{C}$ and $\mathrm{D}$ are given by Eqs. (29), (30) and (31), respectively.

$$
\begin{aligned}
& \mathrm{B}=0.85 f_{\mathrm{cd}} b_{\mathrm{eff}}-\frac{0.0035}{2} t_{\mathrm{w}} E_{\mathrm{sh}}\left(1+\frac{\varepsilon_{\mathrm{sh}}}{0.0035}\right)^{2} \\
& \mathrm{C}=0.0035 E_{\mathrm{sh}}\left(1+\frac{\varepsilon_{\mathrm{sh}}}{0.0035}\right)\left[b_{\mathrm{f}} t_{\mathrm{f}}+t_{\mathrm{w}}\left(h_{\mathrm{c}}+h_{\mathrm{a}}\right)\right]-f_{\mathrm{y}} A_{\mathrm{a}} \\
& \mathrm{D}=-0.0035 E_{\mathrm{sh}}\left(h_{\mathrm{c}}+h_{\mathrm{a}}\right)\left[b_{\mathrm{f}} t_{\mathrm{f}}+\frac{t_{\mathrm{w}}}{2}\left(h_{\mathrm{c}}+h_{\mathrm{a}}\right)\right]
\end{aligned}
$$

where $f_{\text {cd }}$ is the design concrete (cylinder) compressive strength, $b_{\text {eff }}$ is the effective width of the concrete slab, $t_{\mathrm{w}}$ and $t_{\mathrm{f}}$ are the web and flange thickness of the steel beam, respectively, $b_{\mathrm{f}}$ is the flange width of the steel beam, $h_{\mathrm{a}}$ and $h_{\mathrm{c}}$ are the depth of the steel beam and the concrete slab, respectively, and $f_{\mathrm{y}}$ and $A_{\mathrm{a}}$ are the yield stress and cross-sectional area of the steel section, respectively.

(2) Determine the neutral axis position $y_{\mathrm{csm}, \mathrm{a}}$ assuming that steel failure governs the deformation capacity (i.e. the strain at the outer fibre of the steel section reaches the limiting strain of $15 \varepsilon_{\mathrm{y}}$ )

$$
\begin{aligned}
& y_{\mathrm{css}, \mathrm{a}}=\left[f_{\mathrm{y}} A_{\mathrm{a}}+E_{\mathrm{sh}}\left(15 \varepsilon_{\mathrm{y}}-\varepsilon_{\mathrm{sh}}\right) b_{\mathrm{f}} t_{\mathrm{f}}\right. \\
& \left.+\left(E_{\mathrm{sh}} / 2\right)\left(15 \varepsilon_{\mathrm{y}}-\varepsilon_{\mathrm{sh}}\right) t_{\mathrm{w}}\left(h_{\mathrm{c}}+h_{\mathrm{a}}\right)\left(1-\varepsilon_{\mathrm{sh}} / 15 \varepsilon_{\mathrm{y}}\right)\right] /\left[0.85 f_{\mathrm{cd}} b_{\mathrm{eff}}\right. \\
& \left.+\left(E_{\mathrm{sh}} / 2\right)\left(15 \varepsilon_{\mathrm{y}}-\varepsilon_{\mathrm{sh}}\right) t_{\mathrm{w}}\left(1-\varepsilon_{\mathrm{sh}} / 15 \varepsilon_{\mathrm{y}}\right)\right]
\end{aligned}
$$

(3) Calculate the corresponding limiting curvatures $\kappa_{\mathrm{csm}, \mathrm{c}}$ and $\kappa_{\mathrm{csm}, \mathrm{a}}$ for concrete failure and steel failure, respectively

$$
\begin{aligned}
\kappa_{\mathrm{csm}, \mathrm{c}} & =\frac{0.0035}{y_{\mathrm{csm}, \mathrm{c}}} \\
\kappa_{\mathrm{csm}, \mathrm{a}} & =\frac{15 \varepsilon_{\mathrm{y}}}{h_{\mathrm{c}}+h_{\mathrm{a}}-y_{\mathrm{csm}, \mathrm{a}}}
\end{aligned}
$$

The critical curvature $\kappa_{\text {csm }}$ is identified as the lower value of $\kappa_{\mathrm{csm}, \mathrm{c}}$ and $\kappa_{\mathrm{csm}, \mathrm{a}}$.

(4) Determine the moment capacity $M_{\mathrm{csm}, \mathrm{c}}$ of the composite section using the critical $\kappa_{\mathrm{csm}}$ and its corresponding neutral axis position $y_{\mathrm{csm}}$

$$
\begin{aligned}
& M_{\mathrm{csm}, \mathrm{c}}=\left(f_{\mathrm{csm}}-f_{\mathrm{y}}\right) b_{\mathrm{f}} t_{\mathrm{f}}\left(h_{\mathrm{c}}+h_{\mathrm{a}}-\frac{y_{\mathrm{csm}}}{2}\right) \\
& +f_{\mathrm{y}} A_{\mathrm{a}}\left(h_{\mathrm{c}}+\frac{h_{\mathrm{a}}}{2}-\frac{y_{\mathrm{csm}}}{2}\right)+\frac{t_{\mathrm{w}}}{12}\left(f_{\mathrm{csm}}-f_{\mathrm{y}}\right) \\
& \left(h_{\mathrm{c}}+h_{\mathrm{a}}-\frac{\varepsilon_{\mathrm{sh}}}{\kappa_{\mathrm{csm}}}-y_{\mathrm{csm}}\right)\left[4\left(h_{\mathrm{c}}+h_{\mathrm{a}}\right)+2 \frac{\varepsilon_{\mathrm{sh}}}{\kappa_{\mathrm{csm}}}-y_{\mathrm{csm}}\right]
\end{aligned}
$$

The moment capacities obtained from the proposed analytical method have been compared against a series of experimental results collected from the literature on composite beams with full shear connection [14]. The proposed method has been shown to provide a more accurate prediction of test capacity than the current approach given in EN 1994-1-1 [16], with an average of $5 \%$ resistance enhancement being exploited when the beneficial effect of strain hardening is accounted for.

For composite beams with partial shear connection, a tentative approach utilizing the CSM bending resistance of the bare steel section $M_{\mathrm{csm}}$ and the proposed bending resistance of the composite beam with full connection $M_{\mathrm{csm}, \mathrm{c}}$ has been proposed on the basis of numerical investigations in [14]. Further experimental and analytical research in this area is currently underway.

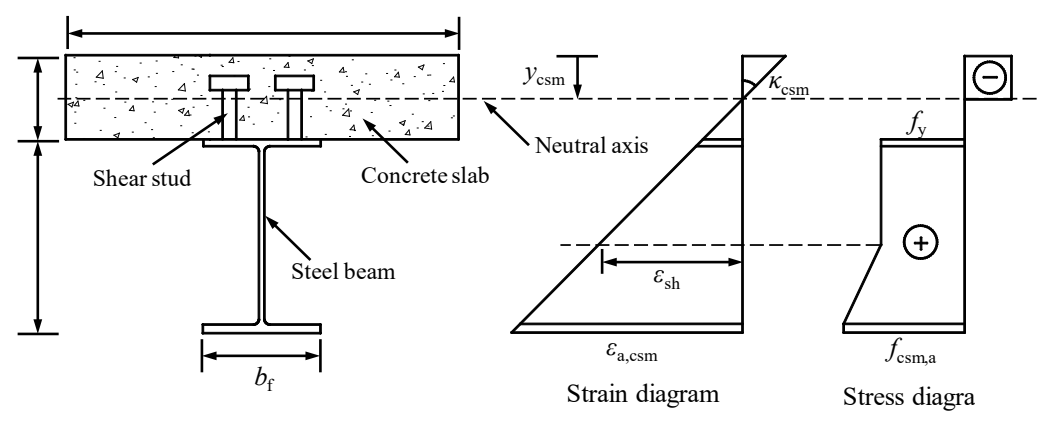

Fig. 7. Strain and stress distributions for a composite beam with full shear connection. 
Yang et al [15] recently extended the CSM to predict the ultimate bending capacities of composite plate girders, whose ultimate hogging flexural state are governed by local buckling of the bottom flange of the steel beam. Depending on the accuracy required for the calculation of the ultimate bending capacities of composite sections under hogging moment, linear and quadratic interpolation equations were also proposed and examined in [15].

The application of the CSM to concrete-filled steel tubular (CFST) members is currently underway. Compared with empty steel tubular sections, local buckling is inhibited in concretefilled specimens due to the presence of the concrete. By allowing for the influence of the concrete infill on the local buckling stress and hence slenderness of the steel section, the deformation capacity can be obtained from the base curve. This can be used to assess compatibility with the concrete failure strain, predict the failure mode and hence determine the resistance of the composite cross-section. This approach is currently being explored.

\section{Conclusions}

The continuous strength method (CSM) is a new design methodology for steel and composite design. The CSM enables a more accurate allowance to be made for the spread of plasticity and the influence of strain hardening; this method has been formally adopted as an alternative design procedure in North American and European design provisions [17,18] for stainless steel design. Expansion of the CSM to systematically cover carbon steel and composite structures is underway. Much work, including extension of CSM to consider indeterminate structures, high strength steels and CFST members under different loading conditions, remains for the further development of the CSM.

\section{References}

[1] Schafer BW, Ádány S. Buckling analysis of cold-formed steel members using CUFSM: conventional and constrained finite strip methods. Proceedings of the 18th International Specialty Conference on Cold-Formed Steel Structures 2006, Orlando, Florida, USA, 39-54.

[2] Seif M, Schafer BW. Local buckling of structural steel shapes. J Constr Steel Res 2010;66(10):1232-1247.
[3] CEN. European Committee for Standardization EN 1993-1-1, Eurocode 3. Design of steel structures - Part 1-1: General rules and rules for buildings. Brussels; 2005.

[4] Afshan S, Gardner L. The continuous strength method for structural stainless steel design. ThinWalled Struct 2013;68:42-49.

[5] Ahmed S, Ashraf M, Anwar-Us-Saadat M. The continuous strength method for slender stainless steel cross-sections. Thin-Walled Struct 2016;107:362-376.

[6] Yun X, Gardner L. Stress-strain curves for hotrolled steels. J Constr Steel Res 2017;133:36-43.

[7] Gardner L, Yun X. Stress-strain curves for coldformed steels. J Struct Eng (Submitted).

[8] Yun X, Gardner L. The continuous strength method for the design of cold-formed steel crosssections. Eng Struct (Submitted).

[9] Yun X, Gardner L, Boissonnade N. The continuous strength method for the design of hotrolled steel cross-sections. Eng Struct 2018;157:179-191.

[10]Bock M, Gardner L, Real E. Material and local buckling response of ferritic stainless steel sections. Thin-Walled Struct 2015;89:131-141.

[11] Su MN, Young B, Gardner L. The continuous strength method for the design of aluminium alloy structural elements. Eng Struct 2016;122:338-348.

[12] Yun X, Gardner L, Boissonnade N. Ultimate capacity of I-sections under combined loading: Experiments and FE model validation. $\mathrm{J}$ of Constr Steel Res (Submitted).

[13] Yun X, Gardner L, Boissonnade N. Ultimate capacity of I-sections under combined loading: Parametric studies and CSM design. J of Constr Steel Res (Submitted).

[14] Gardner L, Yun X, Macorini L, Kucukler M. Hot-rolled steel and steel-concrete composite design incorporating strain hardening. Structures 2017;9:21-28.

[15] Yang F, Liu YQ, Xin HH. Negative bending capacity prediction of composite girders based on continuous strength method. Thin-Walled Struct. (Submitted).

[16]CEN. European Committee for Standardization EN 1994-1-1, Eurocode 4. Design of composite steel and concrete structures - Part 1-1: General rules and rules for buildings. Brussels; 2005.

[17]AISC Design Guide 30: Structural Stainless Steel. American Institute of Steel Construction; 2012.

[18] Design Manual for Structural Stainless Steel, 4th edition. The Steel Construction Institute (SCI), U.K.; 2017. 